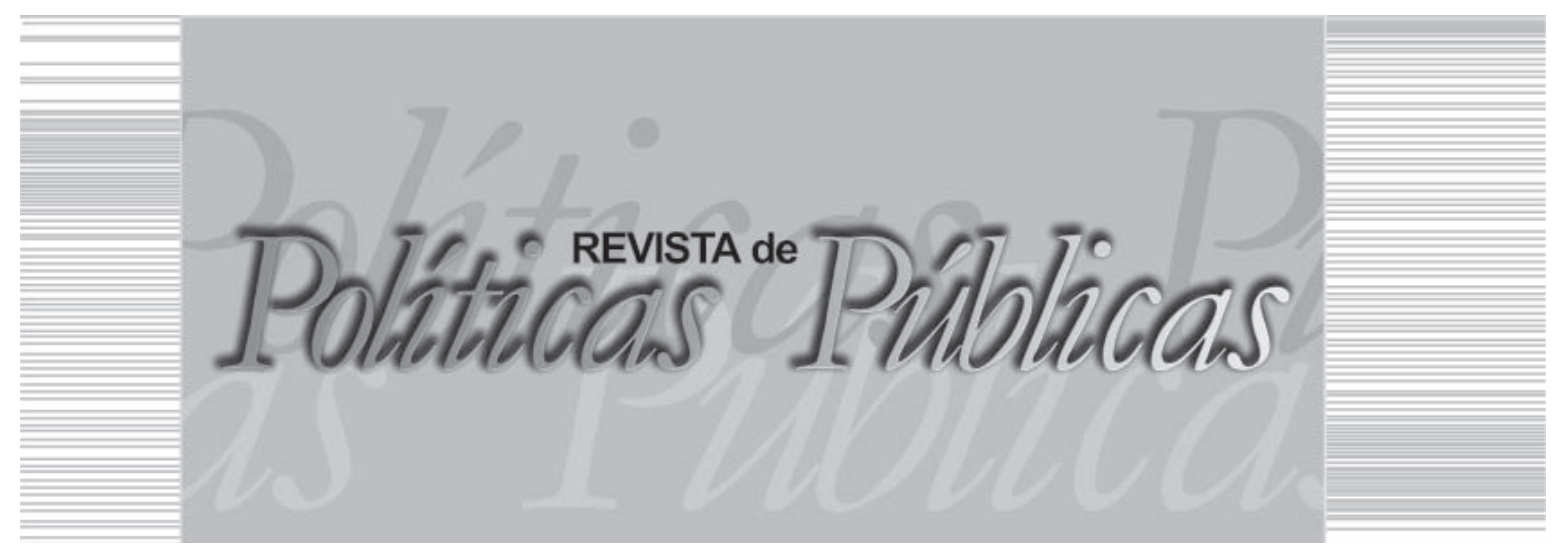

\title{
SERVIÇOS DE SAÚDE DA ZONA LESTE DE TERESINA-PI: mecanismos de uso e gestão de territórios ${ }^{7}$
}

\author{
Paulo Henrique de Carvalho Bueno ${ }^{I}$ \\ Instituto Federal de Educação, Ciência e Tecnologia do Piauí (IFPI) \\ Antônia Jesuíta de Lima² \\ Universidade Federal do Piauí (UFPI)
}

\section{Resumo}

A (re)produção espacial urbana realiza-se a partir de relações sociais tecidas diariamente em que são impressos conteúdos nas formas da cidade. Elementos resultantes dessas tessituras são territórios, territorializações, desterritorializações e reterritorializações. A partir dessa constatação, o artigo objetiva analisar os mecanismos de uso e gestão dos territórios dos serviços de saúde da zona Leste de Teresina, notadamente em seus bairros mais centrais (Fátima, Jóquei e São Cristóvão). Argumenta que os referidos serviços presentes nessa nova centralidade da capital piauiense buscam diferenciar-se dos existentes no centro principal em suas formas uso e gestão, uma vez que se voltam para os segmentos de renda alta da cidade. Metodologicamente, a discussão apoia-se em depoimentos de profissionais e empreendedores de serviços de saúde desses três bairros, obtidos por meio de entrevistas

Palavras-chave: Território, serviços de saúde, Zona Leste de Teresina.

1 Licenciado em Geografia. Doutor em Políticas Públicas. Professor Efetivo no Campus Oeiras do Instituto Federal de Educação, Ciência e Tecnologia do Piauí (IFPI). E-mail: ph21bueno@hotmail.com | Instituto Federal de Educação, Ciência e Tecnologia do Piauí IFPI | Estr. p/ Walace Ferraz, s/n - Uberaba II, Oeiras - PI | CEP: 64500-000

2 Assistente Social. Doutora em Ciências Sociais. Professora Associada do Departamento de Serviço Social e do Programa de Pós Graduação em Políticas Públicas da Universidade Federal do Piauí (UFPI). E-mail: a.je.1@uol.com.br | Universidade Federal do Piauí UFPI | Campus Universitário Ministro Petrônio Portella - Bairro Ininga - Teresina - PI | CEP: 64049-550 


\title{
HEALTH SERVICES OF THE EAST REGION OF TERESINA, PI: MECHANISMS OF USE AND MANAGEMENT OF TERRITORIES
}

\begin{abstract}
The urban space reproduction happens from the social relations daily created in which contents are impressed in the forms of the city. The territories, the territorializations, deterritorializations, and reterritorializations are the resulting elements of this tessitura. Understood as space processes and practices. Based on this finding, it is aimed to analyze the mechanisms of use and management of the territories of health services of the East region of Teresina, mainly in its more central districts (Fátima, Jóquei and São Cristóvão). It is argued that such services, present in this new centrality of the capital of the State of Piauí, seek to set themselves apart from the existing ones downtown, in their forms, use and pattern, once it is dedicated to the segments of high income in the city. Methodologically, the discussion is based on testimonies of professionals and entrepreneurs of health services in these three districts obtained by means of interviews.
\end{abstract}

Key words: Territory, health services, East Region of Teresina.

\section{INTRODUÇÃO}

A (re)produção espacial urbana realiza-se a partir das relações sociais tecidas diariamente em que são impressos conteúdos nas formas da cidade. Como elementos resultantes dessas tessituras estão os territórios, as territorializações, desterritorializações e reterritorializações, entendidos como processos e práticas espaciais. Logo, analisar os processos de (re)construção de territórios na contemporaneidade constitui instrumento teórico de grande valia para a compreensão da dinâmica social em seus âmbitos políticos, econômicos, sociais, culturais e ambientais.

Nesse sentido, objetiva-se analisar os mecanismos de uso e gestão dos territórios dos serviços de saúde da zona Leste de Teresina, notadamente em seus bairros mais centrais (Fátima, Jóquei e São Cristóvão). Argumenta-se que os referidos serviços presentes nessa nova centralidade da capital piauiense buscam diferenciar-se dos existentes no centro principal em suas formas uso e gestão, uma vez que se voltam para os segmentos de renda alta da cidade. Metodologicamente, a discussão apoia-se em depoimentos de profissionais e empreendedores de serviços de saúde desses três bairros, obtidos por meio de entrevistas. Assim, estrutura-se o artigo em 1) discussão 
REVISITANDO A TEORIA E COMPREENDENDO A PRÁTICA: análise de casos

de pagamento por serviços ambientais

teórica sobre território; 2) análise dos mecanismos de uso e gestão dos territórios dos serviços de saúde na zona Leste e, por fim, 3) as conclusões.

\section{TERRITÓRIO E SUA RELAÇÃO COM O ESPAÇO URBANO}

Haesbaert (1995, 2002, 2003, 2006, 2007, 2010, 2011), Saquet $(2010,2011)$ e Saquet e Souza (2009) têm se destacado na discussão conceitual de território e sua aplicabilidade para o entendimento da produção espacial, os quais, mesmo baseando-se em fontes diferentes, possuem suas proximidades discursivas. As reflexões de Haesbaert visam discutir território em uma perspectiva ontológica e não somente como um instrumento de análise da realidade. Nesse sentido, o autor discute as dimensões políticas e culturais incorporadas à dimensão econômica do território, o que o leva a compreendê-lo como a dimensão espacial das relações sociais e o conjunto de representações sobre o espaço, ancorando-se na discussão lefebvriana de dominação e apropriação espacial, em que busca entender o território em uma visão integradora. Na verdade, a palavra território nasce com uma dupla conotação - material e simbólica - mas mantendo em comum a noção de dominação. Nesse sentido, a ideia de identificação e apropriação espacial via territórios construídos cotidianamente pela sociedade remete ao poder, que é imanente na construção de territórios. Destarte, deve-se distinguir os sujeitos que exercem o poder efetivamente e que controlam o(s) espaço(s), assim como os processos sociais que o(s) compõe $(\mathrm{m})$ para compreender o território e os processos de (des)territorialização. (HAESBAERT, 2007).

A concepção mais antiga, e pouco utilizada na atualidade de território, refere-se a ele com base nas relações sociedade e natureza, particularmente na relação natural dos homens com o ambiente físico, elaborada, principalmente, a partir das proposições ratzelianas, em que o meio acaba por determinar as práticas sociais sobre 0 espaço. (HAESBAERT, 2011; MORAES, 2005).

Atualmente, a ideia de território é compreendida sob três dimensões: 1) política - nela, refere-se às relações entre espaço e poder em geral, assim como as já institucionalizadas jurídico-politicamente, em que o território se constitui em um espaço delimitado, com fronteiras definidas, vinculado, principalmente, ao poder políti- 
co estatal; 2) cultural ou simbólico-cultural - nela, o território é analisado a partir da dimensão simbólica e subjetiva como resultado da apropriação e valorização do espaço vivido; 3 ) econômica - nela, o território é visto como fonte de recursos e incorporado nos conflitos das classes socais e na relação entre capital e trabalho. (HAESBAERT, 2011).

Essas dimensões que conformam o território não são dissociáveis, mas interrelacionadas. Nesse sentido, o desvendamento dos conteúdos e espacialidades dos territórios, assim como dos processos de territorialização, desterritorialização e reterritorialização (T-D-R) ${ }^{2}$ requer uma abordagem que, segundo Haesbaert (2011), considere dois binômios, o materialismo-idealismo e o espaço-tempo. Dessa forma, a noção de território remete à ideia de um espaço delimitado por e a partir das relações de poder, as quais fomentam à identificação e gestão de um grupo social por um dado espaço (HAESBAERT, 1995) e envolvem as dimensões econômicas, políticas, culturais e naturais que permeiam a sociedade.

No âmbito dessas dimensões e suas implicações sobre o território, é que Saquet (2010, 2011) e Saquet e Souza (2009), baseado na literatura italiana e suas nuances com a brasileira, principalmente nos estudos de Marcelo Lopes de Sousa e Rogério Haesbaert, visa teorizar e construir de forma efetiva o conceito de território. Para o autor, o território precisa ser analisado em suas dimensões políticas, econômicas e culturais numa perspectiva relacional, em que as relações de poder contidas nas relações sociais se fazem presentes numa dialética de dominação e apropriação, o que acaba por configurar o território como uma espacialidade fruto das relações socioespaciais, como ideia e matéria.

A compreensão de território como produto da relação espaço-tempo implica analisar as formas espaciais empreendidas pela sociedade em um dado momento e as ações necessárias à sua constituição e manutenção. Destarte, para o entendimento do território, deve-se partir, conforme Saquet (2010), de abordagens relacionais-processuais em que se faz necessário vislumbrar o movimento histórico e as várias escalas dos processos de (re)construção dos territórios, enfim, deve-se analisá-lo como matéria e ideia, dimensões indissociáveis.

Com efeito, a abordagem relacional-processual deve ser complementada com a ideia de espaço como híbrido, uma vez que ela 
REVISITANDO A TEORIA E COMPREENDENDO A PRÁTICA: análise de casos

de pagamento por serviços ambientais

fornece elementos primordiais para os estudos do espaço geográfico e do território. Nessa direção, o território é concebido por meio da "[...] imbricação de múltiplas relações de poder, do poder mais material das relações econômico-políticas ao poder mais simbólico das relações de ordem mais estritamente cultural.” (HAESBAERT, 2011, p. 79).

As reflexões de Haesbaert (1995, 2002, 2003, 2006, 2007, 2010, 2011), Saquet $(2010,2011)$ e Saquet e Souza (2009) sustentam que o território não é somente uma forma que se constrói e que se configura nas espacialidades humanas, mas se constitui, sobremaneira, em uma relação social mediada e moldada na/pela materialidade espacial. Ou seja, é a sociedade que anima, funcionaliza, simboliza e significa as formas espaciais, configurando-lhes conteúdo, seja em nível coletivo, seja individual, o que implica dizer que território, T-D-R se concretizam no e pelo movimento social.

A ideia de constituição das territorializações em movimento, realizada pela sociedade a partir da dominação e apropriação espacial, significa, também, que os sujeitos devem controlar os fluxos e criar referenciais espaciais que os identifiquem. Nessa senda, afirma-se que os territórios comportam em si os processos de desterritorialização e de reterritorialização, e o tornam, de acordo com Haesbaert (2011, p. 126-127), "[...]um ato, uma ação, uma relação, um movimento (de territorialização e desterritorialização), um ritmo, um movimento que se repete e sobre o qual se exerce um controle."

A discussão dos processos de T-D-R implica analisar as relações de poder que se estabelecem, se conflitam e se tornam consensuais no jogo das relações sociais, uma vez que o poder se encontra, também, nas microrrelações sociais. Nesse sentido, o poder passa a existir entre os sujeitos sociais quando eles se unem, desaparecendo com a dispersão desse grupo. Raffestin (1993), em sua análise da geografia do poder e suas repercussões sobre a produção espacial do território, infere que o poder é objetivado por meio de relações sociais de dominação. Nessa senda, as ações humanas sobre um dado espaço implicam a consolidação de territorialidades a partir da configuração de "[...] malhas, nós e redes, delimitando campos de ações, de poder, nas práticas espaciais e constituem o território, como materialidade." (SAQUET, 2010, p. 75-76, grifo do autor).

As dinâmicas de construção de redes que delimitam campo de ações e de poder dos agentes produtores do espaço na (re)pro- 
dução de territórios ensejam que se relacionem as transformações que o processo de globalização encerra nos movimentos de T-D-R, uma vez que as redes atuais de comunicação instantânea globalizada permitem a configuração de "[...] territórios descontínuos, fragmentados, superpostos, bastantes distintos da territorialização dominante da modernidade clássica." (HAESBAERT, 2011, p. 281).

A ideia de territórios descontínuos, fragmentados e superpostos e suas relações com o processo de globalização, discutida em Haesbaert (2011), se sustenta nos avanços tecnológicos, nos meios de transportes ou nos de telecomunicações, os quais possibilitam novas configurações de redes, materiais e imateriais. Assim, de acordo com Santos $(2003)^{3}$, o território deve ser tomado a partir do seu uso e dos atores que deles se utilizam, o que implica a valorização diferenciada dos espaços pelo capital. Essas diferenças consistem nas infraestruturas que os lugares oferecem para a reprodução e organização das relações capitalistas de produção. Logo, entre o território e globalização, afirma Santos (2003, p. 23), "[...] cria-se uma relação de causalidade em benefício dos atores mais poderosos, dando ao espaço geográfico um papel inédito na dinâmica social."

A ideia da complexidade que a globalização impõe às práticas de territorialização e desterritorialização põe em evidência que o próprio espaço tornou-se condição, meio e resultado da produção e reprodução das relações capitalistas. (CARLOS, 1992). Portanto, a apreensão desses conceitos requer o entendimento de que "[...] uma territorialização ou desterritorialização é, sempre e em primeiro lugar, um processo que envolve o exercício de relações de poder e a projeção dessas relações no espaço [...]" (SOUZA, 2013, p. 102)4. Compreender, assim, o território e a territorialização como processo, leva à noção de que a territorialização comporta a (i)materialidade das formas e relações sociais, ou seja, as formas estão nos conteúdos e nas territorialidades e vice versa. (SAQUET, 2010).

A ideia de (i)materialidade do território exige que se pense nas articulações entre o substrato físico e as ações humanas que nele são tecidas diariamente pelos diversos agentes produtores do espaço, e as diversas inter-relações entre o local e o global. É que, de acordo com Saquet (2010, p. 163, grifos do autor), o território "[...] é desconstruído e reproduzido, num único processo [...]. O território é multiescalar e multitemporal; processual-relacional; identidade/ unidade e movimento $[\ldots] "$. 
Por conseguinte, ao pensar em território e em sua construção, é necessário entender que ele se define "[...] antes de tudo com referência às relações sociais (ou culturais, em sentido amplo) em que está mergulhado, relações estas que são sempre, também, relações de poder." (HAESBAERT, 2006, p. 54). Contudo, não se pode esquecer que essas relações de poder são, primeiramente, mediadas pelo espaço, e mediação espacial não significa apenas o substrato físico determinante dos comportamentos sociais, posto que ele serve como base da (re)produção social da vida cotidiana e influencia os relacionamentos entre as pessoas e entre elas e os espaços que as rodeiam. Então, o espaço físico constitui-se como produtor e produto de uma dada realidade social, estabelecendo-se em uma dialética infindável, daí poder afirmar-se que refletir sobre o território implica examinar as suas internalidades e externalidades. (HAESBAERT, 2011).

É, pois, numa perspectiva de dinamicidade, marcada por ritmos de circulação e produção do território, que se o entende como relacional, ou seja, uma relação complexa entre os processos sociais e o espaço material, envolvendo, portanto, "[...] o movimento, a fluidez, as conexões." (HAESBAERT, 2006, p. 55). A noção de território relacional se assenta na ideia de que, se a produção do território se realiza em um substrato físico, é a natureza das relações humanas que dá sentido à vida do território. Com efeito, relações de poder emergem das práticas sociais empreendidas sobre o espaço, o que revela os conteúdos das formas e permite que se discutam as articulações e desarticulações intra e interurbano, concretizando uma dinâmica local, regional, nacional e global. (HAESBAERT, 2010). Nessa perspectiva é que Souza (1995) afirma que o território torna-se quase que sinônimo de espaço social, entendendo-se a forma como importante, mas não suficiente, para o prisma do olhar geográfico, fazendo-se necessário desvelar o conteúdo nelas impresso.

Logo, o território é apreendido como um espaço definido por e a partir de relações de poder, as quais têm origem nas apropriações e usos dos substratos físicos espaciais, que se materializam nas relações sociais presentes nessa espacialidade, desde sua gênese à sua gestão. (SOUZA, 1995). Concebendo-o assim, a materialidade do território é dada por objetos que têm uma gênese técnica, um conteúdo técnico e se inter-relacionam na condição de técnica, seja na sua realização, seja em sua funcionalidade. (SANTOS, 2008). Discutir a gestão do território, conforme Corrêa (1992), é analisá-lo como um conjunto de práticas espaciais objetivadas à criação e ao controle da 
organização espacial, seja em suas formas, seja em suas funções, seja na distribuição espacial que visam a existência e reprodução da sociedade.

Pensar a gestão do território como mecanismo que viabiliza a existência e reprodução da sociedade significa compreender os agentes produtores do espaço e suas ações ao longo do tempo, fazendo-se necessário analisar os processos e práticas espaciais. (CORRÊA, 2007). Nesse sentido, os produtores do espaço - proprietários fundiários, promotores imobiliários, detentores dos meios de produção, Estado e grupos sociais excluídos (CORRÊA, 1989) - agem ora de forma articulada ora conflituosa, em determinados momentos, na busca de manutenção de reprodução do sistema, seja no intento de maior equidade social, seja na manutenção das desigualdades existentes.

A produção e reprodução de territórios no tecido citadino pelos grupos sociais geram, cotidianamente, novos (re)arranjos espaciais. Nessa direção, a (i)materialidade dos territórios pode ser compreendida a partir das configurações de novas centralidades que se constituem na cidade, sejam as voltadas para uso residencial, sejam para uso comercial ou de prestação de serviços, o que torna, nos dizeres de Santos (2008), para a reprodução do capital determinados lugares mais atrativos que outros.

3 SERVIÇOS DE SAÚDE DA ZONA LESTE: mecanismos de uso e gestão de territórios

Teresina vivencia, principalmente desde os anos de 1990, uma reestruturação urbana e da cidade, que dinamiza sua produção espacial em diversos setores - habitacional, infraestrutura viária, comercial e de serviço, dentre outras. Nessa dinâmica, os serviços de saúde participam com novas configurações por meio da territorialização em outros espaços da urbe, o que lhes redimensiona a centralidade. A formação de uma centralidade dos serviços de saúde em Teresina remonta à implantação do Hospital Getúlio Vargas (HGV), em 1941. Atualmente, esse complexo hospitalar do HGV inclui o Hospital Infantil, o Hemocentro do Piauí e um ambulatório. Nas suas proximidades estão instalados o Hospital de Doenças Tropicais Natan Portela, as Escolas de Medicina das Universidades Federal e Estadual do Piauí (UFPI/UESPI). Considerado o maior investimento público em saúde do estado (RAMOS, 2003), tornou- 
REVISITANDO A TEORIA E COMPREENDENDO A PRÁTICA: análise de casos

de pagamento por serviços ambientais

-se o HGV um fator determinante na formação da centralidade interurbana e intraurbana desses serviços na capital, pois, ao longo das décadas, atraiu outras atividades congêneres para as proximidades, configurando, assim, um centro dos serviços de saúde, para o qual faz convergir uma gama de fluxos que se (re)produz cotidianamente e constitui uma das características que, conforme Lefebvre (2008), qualificam um espaço como centro.

Durante os anos de 1960 e 1970, a iniciativa privada se destacou na oferta desses serviços, com a instalação do Hospital Aliança Casamater e da Clínica São Lucas e, posteriormente, com os Hospitais Santa Maria e São Marcos. A década de 1980 marca a expansão da rede de serviços de saúde nessa área, com o surgimento de clínicas privadas - Clinefro, Clínica Santa Clara e Clínica Santa Fé - voltadas para o diagnóstico médico, o que conferiu uma densidade maior ao espaço. Ao longo das décadas de 1990 e 2000, constroem-se o Hospital de Terapia Intensiva (HTI), no bairro Marquês (zona Centro) e o Hospital das Clínicas de Teresina, no bairro Primavera (zona Norte), áreas adjacentes ao bairro Centro. Esses empreendimentos, instalados nas proximidades do HGV, propiciaram, conforme Corrêa (1989), a formação de uma coesão espacial de atividades de serviços, o que reforçou a configuração da centralidade do setor de saúde da capital. (BUENO, 2008; FAÇANHA, 2009; TERESINA, 2002). Verifica-se, assim, que os grandes hospitais localizados no centro formam um complexo de serviços de saúde, com atendimentos de média e alta complexidade que, ao longo dos anos, atraiu outros empreendimentos complementares, compondo o atual centro de serviços de saúde de Teresina.

Essas práticas espaciais de construção de estabelecimentos que ofertam serviços de saúde consolidaram um processo espacial de (re)localizações de atividades num dado espaço da cidade, no caso o bairro Centro. Os serviços de saúde prestados nessa área consultas, exames laboratoriais e clínicos e cirurgias, dentre outros atraem grande quantidade de usuários (BUENO, 2008; FAÇANHA, 2009; TERESINA, 2002) e concorreram para a conformação de um centro na prestação desses serviços, à medida que produzem fluxos permanentes de pessoas, mercadorias e informações. (SPÓSITO, 1991, 1996, 2002; VILLAÇA, 2001).

$\mathrm{Na}$ verdade, verifica-se que os estabelecimentos de saúde se espraiam por todas as zonas da cidade e por quase todos os bairros. 
Contudo, alguns espaços se destacam nessa oferta, além do centro. Na zona Sudeste, o Itararé possui 23 empreendimentos (2,7\%), na Sul, o Lourival Parente tem $8(1,0 \%)$, na Norte, o Mocambinho aparece com $6(0,7 \%)$ dos 848 estabelecimentos existentes na capital. Já a zona Leste é a que possui maiores quantidades depois do centro, posto que $55(6,5 \%)$ se situam no bairro Jóquei, $24(2,9 \%)$ no bairro Fátima, $12(1,4 \%)$ no São Cristóvão, 8 ( $0,9 \%)$ no São João, 7 ( $0,8 \%)$ no Horto, $4(0,5 \%)$ no Noivos e $3(0,4 \%)$ no Morada do Sol, o que totaliza 113 estabelecimentos ou $13,3 \%$ do total. Enfim, apesar de outros bairros também ofertarem serviços de saúde, há uma densidade maior na zona Leste, principalmente em sua área mais central. (BRASIL, 2014).

A zona Leste de Teresina despontara, desde os fins da década de 1950, como propícia à moradia das classes sociais detentoras de renda alta. Mas é a partir dos anos de 1970 que essa região da cidade intensifica sua diferenciação socioespacial, traduzida, na produção de unidades habitacionais de alto valor econômico e em atividades comerciais e de serviços (shoppings, lojas de decoração, revendedoras de carros novos, restaurantes, bares e casas de shows requintadas) voltadas especificamente para segmentos de renda alta.

O uso e a gestão dos territórios dos serviços de saúde na zona Leste evidenciam práticas e dinâmicas que visam a atender um público específico, os consumidores solventes do serviço ofertado, que se diferenciam, em diversos aspectos, dos existentes na área central da cidade. Na verdade, o público que consome esses serviços, como revelam os dados, não se restringe aos moradores da zona Leste, mas abrange pessoas de toda a cidade, do interior do Piauí e de outros estados, o que demonstra que a sua capacidade de atração promove um fluxo significativo. Nessa direção, discutir uso e gestão do território implica compreender que "[...] a criação e manutenção de diferenças espaciais através das quais as diferenças econômicas e sociais se realizam, são legitimadas e se reproduzem [...]" (CORRÊA, 1992, p.35).

No sentido de gestão das diferenças espaciais, tem-se que um dos elementos distintivos desses territórios é o predomínio de planos de saúde como forma de acesso aos serviços ofertados, aspecto que também favorece o grande fluxo de usuário. Outro que chama a atenção é a existência de profissionais que só atendem com pagamento em espécie. Destarte, as formas de pagamentos revelam a apropria- 
REVISITANDO A TEORIA E COMPREENDENDO A PRÁTICA: análise de casos

de pagamento por serviços ambientais

ção do espaço por classes de renda alta e a sua restrição às camadas sociais de renda baixa, que não dispõem de recursos suficientes para pagamento de planos de saúde ou outras formas de aquisição dos serviços, uma das marcas peculiares do público-alvo que busca tratamentos de saúde na zona Leste de Teresina. Sobre a dinâmica desses mecanismos demarcadores, declaram alguns entrevistados:

\begin{abstract}
Eu só trabalho com paciente particular, não trabalho mais com nenhum tipo de convênio. Por um motivo bem simples: quando você trabalha com convênio, você não sabe se recebe. Como tive alguns problemas com convênio, nunca mais quis trabalhar com nenhum. Os maiores problemas dos convênios, na minha concepção, são dois: primeiro, é o valor, que é baixo; o segundo é a demora para pagamento. Então, se você é atendido hoje por qualquer convênio, a consulta que foi feita hoje, só daqui a três meses eles vão pagar. Então, é um mês pra faturamento e um mês para pagamento. Então, qualquer economista que você for perguntar vai dizer que você está fazendo um mau negócio. Então, eu desisti. (Informação verbal) ${ }^{5}$.

Aqui nós temos dois tipos de pacientes. Trabalhamos com os pacientes de consultas por convênios, têm alguns convênios aqui mesmo da clínica. Mas o grande movimento nosso, dessa região, é da UNIMED. Até porque, aqui, nós temos mais de 20 médicos cooperados da UNIMED; então, temos, talvez, a concentração de médicos cooperados e de pacientes da UNIMED. Temos outros convênios que são atendidos aqui em menor escala, como os pacientes do IAPEP, tem bastante gente também que é credenciado do IAPEP aqui. Então, são pacientes de planos, e os particulares. A cobrança aos planos de saúde se dá pela própria clínica, os particulares pagam com dinheiro ou cartão de crédito, todas as vias de pagamento são aceitas aqui. (Informação verbal) ${ }^{6}$.
\end{abstract}

As formas de pagamento revelam, também, um dos aspectos do meio técnico-científico-informacional (SANTOS, 2008), centrado na formalidade das relações capitalistas e no uso do dinheiro virtual. Trata-se, conforme Saquet (2011), da face (i)material do território, no caso da área prestadora dos serviços de saúde da zona Leste, embora outras formas de quitação sejam verificáveis, o que acaba se constituindo, para usar a reflexão de Santos (2004), uma das faces do circuito inferior da economia urbana, que também se realiza na região nobre de Teresina. Outra característica enfatizada pela maioria dos entrevistados, do uso e gestão desses territórios, reside no fato de que os pagamentos de procedimentos pelo SUS são pouco compensatórios, daí sua baixa aceitação, um dado que diferencia o 
atendimento aos usuários do Centro da cidade e aos da zona Leste, como revela o seguinte depoimento:

O atendimento pelo SUS não compensa [...]. Atendimento pelo SUS tem que ser em hospital público, a não ser que eu tenha alguma filantropia. Então, a nossa ideia aqui é não atender uma classe diferenciada, privilegiada economicamente, estamos abertos para atender desde o paciente mais simples. É óbvio que não atendemos SUS. Se ele tiver ou possa pagar consulta ou se ele tiver o plano de saúde, até com o paciente de poder aquisitivo mais alto, não há essa distinção, certo? Existe uma seleção de que na zona Leste você tem uma população com mais convênio, comparado com as outras áreas da cidade, a Sudeste, a Norte, você terá uma população maior com convênio. Esse paciente tem convênio, tem como pagar o plano de saúde todo mês. Muitas vezes, quando ele precisa e não tem o médico no plano de saúde, não tem porque pagar consulta particular, pois paga plano de saúde, certo? Como lhe falei, como você está um pouco mais distante do Centro, tem que pegar um mototáxi ou um táxi ou até mesmo pegar um ônibus e depois se locomover um pouco mais, e isso afasta aquele paciente que vem do município distante e que se hospeda pelo Centro. Isso é uma questão, ou talvez os pacientes que se hospedam no Centro eles não sabem se locomover na cidade ou o dinheiro é pouco, não se pode gastar muito com locomoção ou o nível, infelizmente, o nível sociocultural desses pacientes é baixo, e ele não sabe se desenrolar na cidade, não tem desenvoltura para tomar as iniciativas sozinhas, então precisa de alguma outra pessoa, que muitas vezes é o dono de pensão. (Informação verbal)?

$\mathrm{Na}$ verdade, os dados mostram, também, que uma das diferenciações do acesso aos serviços de saúde na zona Leste se dá nos níveis intraurbano e interurbano, sob dois aspectos: os teresinenses, principalmente os detentores de rendas médias e altas, podem optar pela sua utilização ou na área central ou nesse novo espaço de concentração, enquanto os residentes em outros municípios, particularmente os que têm poucos recursos financeiros, se valem dos serviços disponíveis no centro principal. Com efeito, verifica-se que o grande fluxo de usuários no centro principal dos serviços de saúde gera maiores dificuldades de acessibilidade e comodidade, o que acaba por tornar os serviços da zona Leste mais atrativos para os que possuem condições financeiras de pagar pelo atendimento.

As informações obtidas nas entrevistas permitem inferir o quão a saúde tornou-se uma mercadoria disposta para aqueles que podem pagar. Essa situação enseja, segundo reflexões de Bueno 
REVISITANDO A TEORIA E COMPREENDENDO A PRÁTICA: análise de casos

de pagamento por serviços ambientais

(2008), práticas, dentre tantas outras, de territorialização dos donos de pensões, assim como de agenciadores de clientes, com os profissionais médicos e outros agentes, fato bastante presente no Centro da cidade, como destacado na reportagem do Portal AZ intitulada Médicos e donos de pensões montam esquema para explorar doentes (VIREIRA, 2015).

$\mathrm{Na}$ zona Leste, apesar de ainda pouco visível como prática, disse um dos entrevistados que já foi tentado por esses agenciadores - dono de pensão -, uma das evidências da busca de territorialização deles nessa nova área de centralidade de serviços. Contudo, essas investidas não se concretizaram ainda, fato comprovado pela inexistência de casas de pensões voltadas à hospedagem de usuários dos serviços de saúde nos bairros centrais da zona Leste. Conforme Bueno (2008), explica-se essa ausência porque se o público dessas pensões são pessoas do interior do estado, que possuem poucos recursos financeiros para a utilização de serviços de saúde, fica inviável realizar grandes investimentos, como a compra ou aluguel de uma casa nos bairros Fátima, Jóquei ou São Cristóvão, para ofertar tais serviços.

Quanto às formas de utilização e gestão dos espaços pelos profissionais de saúde, estas se diversificam. No hospital, o uso consiste no aluguel de leitos e salas de cirurgias por médicos que trabalham em outros estabelecimentos. Uma vez acordada entre profissional e paciente a realização de uma dada cirurgia, contata-se o hospital e agenda-se o uso de seu espaço, cujos pagamentos se darão por planos de saúde, dinheiro em espécie, cartão de crédito ou débito. O trabalho na instituição funciona como aberto ao corpo clínico, significando, conforme seu proprietário, que:

[...] os médicos cadastrados no hospital podem usar as instalações e atender seus pacientes. Nós temos duas maneiras do paciente chegar até o hospital: através do serviço de urgência ou através de procedimentos eletivos. Os procedimentos eletivos em geral são cirúrgicos, não existe um atendimento eletivo clínico; por exemplo, a pneumonia é uma condição clínica que não se programa para internar, não se programa para tratar uma pneumonia, mas por uma urgência infecciosa, que é um quadro de pneumonia. Isso é uma forma de internar, a outra é você ter, por exemplo, uma pedra na vesícula, que o seu médico indica a cirurgia, você agenda a cirurgia para daqui a 20 dias, 30 dias e se interna. Então, existem esses dois tipos de atendimento: urgência e procedimentos eletivos. (Informação verbal) ${ }^{8}$. 
Outra forma de funcionamento dos serviços de saúde da zona Leste são os prestados em consultórios individuais e instalações coletivas que abrigam diversas especialidades médicas. Os mecanismos utilizados nesses casos são os aluguéis de salas, seja de forma permanente, seja por horários de trabalho. Nessa direção, a oferta torna-se menos onerosa para o profissional, que não precisa arcar com custos de aquisição de terreno, construção e outros dispêndios. Além da diminuição de custos para o profissional, essa coesão de serviços em um único empreendimento facilita o acesso para o usuário, uma vez que se realizam diversos procedimentos, tais como consultas médicas e exames clínicos, sem necessidade de deslocamento. Essas formas contratuais e de uso são ressaltadas por alguns entrevistados:

Existem duas formas de contratos. Existe um contrato no qual o dono da clínica ganha uma porcentagem da produção, sendo assim o funcionário, no caso o médico, não precisa ter um valor fixo de pagamento mensal. Isso ocorre na maioria das clínicas, a grande maioria. E existem os contratos em que você paga o valor fixo para um aluguel de uma sala, que é uma minoria, uma grande minoria realmente, porque a maioria é por produtividade. De um ano para cá, essa produtividade começou a ser de pessoa jurídica para pessoa jurídica, dificilmente você vai encontrar uma pessoa jurídica com uma pessoa física. (Informação verbal) ${ }^{9}$.

Aqui é um conjunto de médicos [...]. São 12 sócios, mas tem mais 30 médicos que atendem aqui, que locam as salas, alugam as salas e, então, vão, fazem seu atendimento, utilizam alguns planos de saúde que são da própria clínica e atendem seus pacientes particulares também. (Informação verbal) ${ }^{10}$.

Aqui nós temos hoje em torno de 22 salas nesse prédio, mais 12 lá no outro e o uso é feito sob a forma de locação, feita pelas leis do mercado (oferta e procura), algo em torno de $\mathrm{R} \$ 2.200,00$, e, além disso, compartilhamos o condomínio, a manutenção, essas coisas todas que fazem parte de qualquer locação. (Informação verbal) ${ }^{11}$.

O valor do aluguel destacado dá uma dimensão da rentabilidade que o setor de saúde instalado na zona Leste proporciona. O caso do empreendimento de um dos entrevistados gera algo em torno de $\mathrm{R} \$ 74.800,00$ mensais (34 salas alugadas a $\mathrm{R} \$ 2.200,00$ por mês). Nessa direção, investimentos em formas arquitetônicas que abrigam diversas especialidades médicas, assim como edifícios funcionais, encontram nessas possibilidades de auferirem altos valores de retor- 
REVISITANDO A TEORIA E COMPREENDENDO A PRÁTICA: análise de casos

de pagamento por serviços ambientais

no do capital investido uma de suas motivações para a produção de territórios e (re)produção do espaço urbano nessa região da cidade.

A existência de espaços voltados para ofertar diversas especialidades médicas aumenta as possibilidades de deslocamento de profissionais e empreendimentos do centro da cidade para a área dessa nova centralidade. Assim, grande parte dos consultórios, laboratórios e clínicas são filiais dos já existentes no Centro, uma vez que, conforme o empresário e médico Flávio Santos (apud FONTENELE, 2015, p.1),

[...] muitas clínicas estão abrindo também na Zona Leste como uma estratégia de mercado, porque nessa área não se atende paciente de fora, mas sim da própria região. $\mathrm{E}$ as empresas estão investindo porque estão vendo esse nicho de mercado e querem suprir essa demanda. Já outros estão investindo em outros bairros, o que é uma estratégia muito interessante, porque se consegue ir para perto do paciente [...].

Na verdade, a instalação de filiais consiste na manutenção e, ao mesmo tempo, na expansão de clientela e território dessas empresas e profissionais. Além disso, alguns empreendedores já constroem para abrigar diversas especialidades, o que amplia as vantagens de lucro, posto que, além do serviço próprio, ainda aluga o espaço para outros profissionais. Essa situação acerca das filiais e outras possibilidades de negócios são destacadas na fala seguinte:

Onde você possa imaginar agora, existem várias clínicas sendo montadas aqui na zona Leste, porque essa é uma evolução natural. O centro está saturado, existe uma demanda, digo, reprimida, aqui na zona Leste, por quê? Porque hoje, quem está se instalando aqui na zona Leste são praticamente os mesmos grupos que estão no centro. São filiais ou transferidos para cá, porque é um inferno você chegar lá no centro hoje, você vai de carro, você fica preso, você não tem estacionamento, é uma coisa de louco. Então, como é que você imagina que você está aqui nessa região e você vai enfrentar aquilo lá? Então, as pessoas começaram a ter consciência de que essa região aqui é margeada pelo rio Poti, avenida João XXIII, Kennedy, ali pelo lado já da universidade existe um núcleo populacional muito grande e crescendo cada vez mais. Então, as pessoas estão se dando conta de que precisam ter um pé aqui também, na zona Leste. (Informação verbal) ${ }^{12}$.

$\mathrm{Na}$ verdade, as atividades comerciais e de serviços presentes nos bairros da zona Leste reforçam a divisão socioespacial, uma vez que há uma diminuição das necessidades de ida ao centro da cidade 
para a resolução de problemas, sejam os ligados a compras, sejam os relacionados aos tratamentos de saúde. De fato, os bairros Fátima, Jóquei e São Cristóvão dispõem de uma rede de serviços e de atividades comerciais que diminui as necessidades de ida ao Centro da cidade, pois atendem à população da zona Leste e de outros territórios da urbe. Ademais, os usuários dos serviços de saúde podem usufruir de outros atributos da área, como lazer e entretenimento, elementos proporcionados, por exemplo, pelos shoppings aí existentes. Acerca dos atributos que diminuem as necessidades de ida até o centro, afirmam alguns dos entrevistados:

\begin{abstract}
O serviço de saúde é um elemento, mas você tem supermercados, você tem bancos, praticamente todos eles, shoppings são do nosso lado, a parte comercial está muito desenvolvida e todas essas avenidas maiores, os restaurantes, sua maioria estão do lado de cá, a universidade é aqui. Então, com certeza, você começa a precisar muito menos ir lá no Centro para fazer qualquer outra coisa. (Informação verbal) ${ }^{13}$.

Aqui na zona Leste é, quer queira, quer não, uma região onde temos muitas oportunidades, por exemplo, de sair à noite, de fazer um lanche, não é? De ir ao shopping, por conta da proximidade, ou seja, localização, não é? De conversar com amigos. O lazer aqui é muito interessante, o entretenimento aqui na zona Leste então, isso é muito bom, claro, e os próprios pacientes, por exemplo, falam que, saindo daqui, têm alguma coisa para resolver, têm um amigo para encontrar, eu vejo essa comodidade [...]. Eu vejo como muito bom, aqui é bem servido de entretenimento e lazer. (Informação verbal) $)^{14}$.
\end{abstract}

Acrescente-se que, quanto mais fluxos convergem para e a partir de um centro, mais investimentos ocorrem nesse espaço, o que lhe reforça a centralidade. Por outro lado, segundo Lefebvre (2008), esse movimento leva à saturação do centro, o que irá requerer outro. É a partir dessa dinâmica urbana corrente que se vislumbra a convergência de atividades comerciais e de serviços, como os de saúde, para os bairros mais centrais da zona Leste de Teresina.

Para proporcionar maior conforto, os prestadores de serviços da zona Leste buscam, na medida do possível, diferenciarem-se no atendimento, construindo uma fidelidade da clientela, além de promover a divulgação do serviço ofertado. Tal diferenciação é perceptível desde a estrutura arquitetônica até as relações entre profissionais e clientes. Para dar maior conforto aos usuários, é comum os empreendimentos congregarem diversas especialidades e a exis- 
REVISITANDO A TEORIA E COMPREENDENDO A PRÁTICA: análise de casos

de pagamento por serviços ambientais

tência de um espaço de convivência, em que se pode dialogar com os demais. Verificou-se, durante a pesquisa de campo, por exemplo, a existência de um pianista, que se apresenta às terças e quintas, em dado espaço. Segundo depoimentos de alguns entrevistados, trata-se de uma estratégia relacionada a uma nova concepção da relação saúde/doença. Ou seja, é uma forma de receber o usuário em um espaço não vinculado somente a doenças.

Essas relações de conquista e manutenção da fidelidade da clientela ensejam práticas que convergem para disputas, principalmente entre empreendedores que ofertam serviços análogos. Enfim, dada a uma quantidade significativa de prestadores de serviços, essa realidade é inevitável, seja como positiva, seja como negativa. $\mathrm{Na}$ verdade, a competição entre os agentes produtores do espaço urbano reflete aspectos inerentes à constituição dos territórios, uma vez que, conforme Haesbaert (2011) e Saquet (2010), as relações que os instituem se dão no e pelo movimento da sociedade. Os dados das entrevistas mostraram que um dos empreendedores visualizou as possibilidades de reprodução das relações de produção para ampliar os lucros, investindo em áreas consideradas propícias, as quais possuem características favoráveis ao desenvolvimento de atividades comerciais e de serviços, como no caso do bairro Jóquei, em Teresina. Para consolidar a territorialização desses serviços, os promotores publicitários difundem e constroem uma imagem positiva, o que acaba por ser mais um elemento de reforço da centralidade e, conforme Carlos (2007) e Corrêa (2007), da diferenciação socioespacial desse subcentro.

Os depoimentos também evidenciam que os serviços de saúde presentes na zona Leste funcionam de forma complementar entre si e aos do Centro da cidade. Nas relações estabelecidas entre os localizados nos bairros Fátima, Jóquei e São Cristóvão, verifica-se que buscam construir e consolidar esses laços, posto que os usuários são, mesmo que de forma sutil, instruídos a utilizarem-se, quando possível, dos seus serviços.

Essas práticas de sugestão de uso dos serviços nos bairros da zona Leste partem da constatação de que existe uma quantidade razoável de prestadores de serviços de saúde, de baixa, média ou alta complexidade. Nos empreendimentos que abrigam diversas especialidades, os usuários são orientados a utilizarem os serviços disponíveis no próprio espaço e, quando inexistentes, indica-se um 
mais próximo, preferencialmente já conhecido pela qualidade. $\mathrm{Na}$ verdade, esses encaminhamentos, formais e informais, contribuem para a produção, uso e gestão dos territórios desses serviços. Sobre essa dinâmica, assim se pronunciaram dois entrevistados:

Procuramos orientar, na medida do possível, nessa região, até porque sabemos que são pessoas daqui. Aumentou muito esses serviços e, assim, a oferta. Hoje, no Jóquei, você passa em quase toda rua e há uma clínica, na avenida já tem. Então, nos últimos cinco anos eu te digo: houve assim uma evolução tremenda. Se você for pelo número de clínicas que se instalaram aqui no Jóquei, não falo em consultórios, falo em clínicas, embora se fale nelas, deve-se perceber a estrutura física maior, não é um consultoriozinho, mas você vê que aumentou muito e isso tem facilitado para nós, porque uma especialidade que não tenho aqui [...], eu encaminho para essa clínica. Isso eu não tenho dúvida, não vou mandar a pessoa para o Centro, a não ser que não tenha nenhum serviço aqui, mas as indicações são feitas aqui para a região Leste. (Informação verbal) ${ }^{15}$.

Olha, depende muito do tipo de serviço que a gente vai utilizar. Quando você precisa de algum exame laboratorial, exames mais simples, que eventualmente não se faz aqui na clínica, ou a gente deixa a critério do paciente ou orienta alguns lugares que são referência nossa, que nós temos mais confiança em utilizar. Quando o evento é internação, depende da prática de cada médico. Eu, pessoalmente, geralmente interno meus pacientes no Hospital São Paulo, interno ali no hospital da UNIMED, uma vez que somos, a maioria daqui, cooperados da UNIMED e no Hospital São Marcos, que são os hospitais que eu trabalho. Os colegas aqui trabalham em outros serviços no Hospital Santa Maria, no hospital lá do PRONTOMED. Então, isso fica mais a critério, mas em geral algum exame de imagem a mais nós encaminhamos para fazer em clínicas que são sabidamente possuidoras de aparelhos de boa qualidade, como a Lucídio Portela, a UDI, o próprio Hospital São Marcos, enfim, depende do tipo de exame. (Informação verbal) ${ }^{16}$.

Os serviços de saúde, em sua nova configuração no espaço urbano de Teresina, buscam incessantemente manutenção, consolidação e ampliação. Para tanto, conforme revelaram os entrevistados, utilizam de diversos mecanismos de promoção e divulgação em que se sobressaem a internet, o rádio, a televisão, os folders e a indicação pessoal.

Os dados das entrevistas mostraram, também, que esse processo de descentralização possui nuances. Uma delas é o fato de que as grandes clínicas ainda não foram para a zona Leste porque no 
REVISITANDO A TEORIA E COMPREENDENDO A PRÁTICA: análise de casos

de pagamento por serviços ambientais

Centro há uma quantidade de usuários maior que nesse novo espaço. Com efeito, é perceptível que as territorializações produzidas nos bairros Fátima, Jóquei e São Cristóvão ainda se centram no diagnóstico e tratamento médico de baixa complexidade (consultórios odontológicos e médicos, clínicas médicas sem procedimentos cirúrgicos, clínicas de fonoaudiologia, psicologia e fisioterapia) e média complexidade (clínicas médicas com procedimentos cirúrgicos ambulatoriais, pronto-atendimento de urgência, exames de imagens extra hospitalares). Isso indica que os serviços de alta complexidade não se descentralizam na mesma proporção, sendo uma das exceções o Hospital São Paulo, visualizado como uma tendência, no caso dos serviços de quimioterapia, exames de tomografia, ressonância magnética e realização de pequenas cirurgias.

\section{CONCLUSÃO}

A partir dos dados, verifica-se que a descentralização dos serviços de saúde para a zona Leste, principalmente para os bairros mais centrais - Fátima, Jóquei e São Cristóvão -, possui como mecanismo a busca de um público social e economicamente diferenciado. $\mathrm{Na}$ verdade, essa região se constitui como espaço mais propício para a (re)produção do espaço urbano e para a instalação de atividades comerciais e de serviços. De fato, a densidade dessas atividades enseja a conformação de um subcentro em que os serviços de saúde funcionam como mais um elemento que lhes caracteriza.

Infere-se, assim, que a produção, uso e gestão dos territórios dos serviços de saúde na região se dá por meio da manutenção e consolidação das diferenças espaciais em que os aspectos econômicos e sociais dos agentes produtores legitimam e reproduzem esse espaço. Essas diferenciações são percebidas, dentre outros, por meio do público consumidor, das motivações para a instalação dos proprietários e profissionais da área de saúde e das formas de acesso aos serviços. Daí que essas características traduzem-se em gestão das diferenciações socioespaciais.

\section{REFERÊNCIAS}

BRASIL. Ministério da Saúde. Banco de dados do Sistema Único de Saúde - DATASUS: Cadastro Nacional de Estabelecimentos de Atenção à Saúde - CNES, 2014. Disponível em:<www.cnes.datasus. gov.br>. Acesso em: 25 mar. 2014. 
BUENO, P. H. C. As casas de pensões do polo de saúde de Teresina: produção espacial e políticas públicas. 2008. 128 f. Dissertação (Mestrado em Políticas Públicas) - Universidade Federal do Piauí, Teresina, 2008.

CARLOS, A. F. A. A cidade. São Paulo: Contexto, 1992.

. A diferenciação socioespacial. Revista Cidades, Presidente Prudente, v. 4, n. 6, p. 45-60, 2007.

CORRÊA, R. L. Corporação, práticas espaciais e gestão do território. Anuário do Instituto de Geociências, Rio de Janeiro, v. 15, p. 35-41, 1992. Disponível em:<http://ppegeo.igc.usp.br/pdf/anigeo/ v15/v15a06.pdf>. Acesso em:15 jun. 2015.

. Diferenciação socioespacial, escala e práticas espaciais. $\overline{\text { Revista }}$ Cidades, Presidente Prudente, v. 4, n. 6, p. 61-72, 2007. . O espaço urbano. São Paulo: Ática, 1989.

FAÇANHA, A. C. Desenvolvimento territorial recente em espaços sub-regionais no Piauí. 2009. 227 f. Tese (Doutorado em Geografia) Universidade Federal de Pernambuco, Recife, 2009.

FONTENELE, M. Especial: polo de saúde de Teresina é referência em atendimento. Cidadeverde.com, Teresina, 2015. Disponível em: $<$ http:/cidadeverde.com/vida/68938/especial-polo-saude-de-teresinae-referencia-em-atendimento>. Acesso em: 12 jun. 2015.

HAESBAERT, R. Concepções de território para entender a desterritorialização. In: SANTOS, M. et. al. Território, territórios: ensaios sobre o ordenamento territorial. Rio de Janeiro: DP\&A, 2006. p.17-38.

. Da desterritorialização à multiterritorialidade. Boletim Gaúcho de Geografia, Porto Alegre, v. 29, n. 1, p. 11-24, 2003.

. Desterritorializacão: entre as redes e os aglomerados de exclusão. In: CASTRO, I. E. de; GOMES, P. C. da C.; CORRÊA, R. L. Geografia: conceitos e temas. Rio de Janeiro: Bertrand Brasil, 1995. p. 165-205.

. O mito da desterritorialização: do fim dos territórios à multiterritorialidade. 6. ed. Rio de Janeiro: Bertrand Brasil, 2011.

. Regional - Global: dilemas da região e da regionalização na Geografia contemporânea. Rio de Janeiro: Bertrand Brasil, 2010.

. Território e multiterritorialidade: um debate. GEOgraphia, Niterói, v. 9, n. 17, p. 19-45, 2007. 
REVISITANDO A TEORIA E COMPREENDENDO A PRÁTICA: análise de casos

de pagamento por serviços ambientais

Territórios alternativos. São Paulo: Contexto, 2002.

LEFEBVRE, H. A revolução urbana. 3 reimp. Tradução: Sérgio Martins. Belo Horizonte: UFMG, 2008.

MORAES, A. C. R. Geografia: pequena história crítica. 20. ed. São Paulo: Annablume, 2005.

RAFFESTIN, C. Por uma geografia do poder. Tradução Maria Cecília França. São Paulo: Ática, 1993.

RAMOS, F. F. Memorial do Hospital Getúlio Vargas: contexto histórico - político - econômico - sociocultural 1500-2000. Teresina: Gráfica do Povo, 2003.

SANTOS, M. A natureza do espaço: técnica e tempo, razão e emoção. 4. ed. São Paulo: EDUSP, 2008.

O espaço dividido: os dois circuitos da economia urbana dos países subdesenvolvidos. 2. ed. São Paulo: EDUSP, 2004.

Por uma outra globalização: do pensamento único à consciência universal. 10. ed. Rio de Janeiro: Record, 2003.

SAQUET, M. A. Abordagens e concepções de território e territorialidade. Revista Geográfica de América Central, Heredia, v. 2 , n. 47e, p. 1-16, 2011. Disponível em:<http://www.revistas.una.ac.cr/ index.php/geografica/article/viewFile/1795/1701>. Acesso em: 3 abr. 2014.

Abordagens e concepções de território. 2. ed., São Paulo: $\overline{\text { Expressão Popular, } 2010 .}$

; SOUZA, E. B. C. de. Leituras do conceito de território e de processos espaciais. São Paulo: Expressão Popular, 2009.

SOUZA, M. J. L. de. O território: sobre espaço e poder, autonomia e desenvolvimento. In: CASTRO, I. E. de; GOMES, P. C. da C.; CORRÊA, R. L. Geografia: conceitos e temas. Rio de Janeiro: Bertrand Brasil, 1995.

Os conceitos fundamentais da pesquisa sócio-espacial. Rio de Janeiro: Bertrand Brasil, 2013.

SPÓSITO, M. E. B. Centralidade intra-urbana. Conjuntura, Presidente Prudente, n. esp., p. 49-52, 2002.

O centro e as formas de expressão da centralidade urbana. Revista Geográfica, Presidente Prudente, n. 10, p. 1-18, 1991. 
Reestruturação da cidade. In: MELO, J. L. (Org.). Região, cidade e poder. Presidente Prudente: GASPERR, 1996.

TERESINA. Prefeitura Municipal. Secretaria Municipal de Planejamento. Teresina Agenda 2015: Plano de Desenvolvimento Sustentável. 2002.

VIEIRA, W. Médicos e donos de pensões montam esquema para explorar doentes. Portal AZ, Teresina, 2015. Notícia geral. Disponível em: $<$ http://www.portalaz.com.br/arimateia $>$. Acesso em: 21 out. 2014.

VILLAÇA, F. Espaço intra-urbano no Brasil. São Paulo: Studio Nobel, 2001

\section{NOTAS:}

1 Essa reflexão é constituinte da Tese de doutorado intitulada Centralidade dos serviços de saúde em Teresina (PI): produção, uso e gestão de territórios na zona Leste da cidade, defendida em 2015, junto ao Programa de Pós-Graduação em Políticas Públicas da Universidade Federal do Piauí.

2 Esses processos geográficos de T-D-R são representados a partir da produção de territórios - territorialização, destruição de territórios (mesmo que temporária) - desterritorialização, e sua recriação - reterritorialização. (HAESBAERT, 2011).

3 O conceito de território em Milton Santos vai tornar-se objeto de uma análise mais profunda em suas obras A natureza do espaço: técnicas e tempo, razão e emoção (2008) e Por uma outra globalização (2003), em que o discute como território usado, em que as contradições atuais do sistema capitalista se revelam com maior nitidez no território.

4 Marcelo Lopes de Souza $(1995,2013)$ discute as concretudes dos múltiplos territórios imersos no estado-nação numa abordagem que leva em conta os aspectos da política e suas inter-relações com os da cultura, o que configura em territórios com uma existência sazonal ou permanente no tempo e no espaço.

5 Depoimento retirado da entrevista com Fisioterapeuta, concedida em 26 de fevereiro de 2015

6 Depoimento retirado da entrevista com Sócio Proprietário e Médico, concedida em 17 de julho de 2015.

7 Depoimento retirado da entrevista com o Proprietário e Médico, concedida em 2 de fevereiro de 2015 .

8 Depoimento retirado da entrevista com o Proprietário e Médico, concedida em 4 de julho de 2015 .

9 Depoimento retirado da entrevista com o Médico, concedida em 26 de junho de 2015.

${ }^{10}$ Depoimento retirado da entrevista com o Proprietário e Médico, concedida em 17 de julho de 2015 . 


\section{REVISITANDO A TEORIA E COMPREENDENDO A PRÁTICA: análise de casos}

\section{de pagamento por serviços ambientais}

${ }^{11}$ Depoimento retirado da entrevista com o Proprietário e Médico, concedida em 11 de fevereiro de 2015.

${ }^{12}$ Depoimento retirado da entrevista com o Proprietário e Médico, concedida em 11 de fevereiro de 2015.

13 Depoimento retirado da entrevista com o Proprietário e Médico, concedida em 17 de julho de 2015 .

${ }^{14}$ Depoimento retirado da entrevista com a Psicológa, concedida em 27 de fevereiro de 2015.

15 Depoimento retirado da entrevista com o Proprietário e Médico, concedida em 11 de fevereiro de 2015.

${ }^{16}$ Depoimento retirado da entrevista com o Proprietário e Médico, concedida em 17 de julho de 2015 . 